\title{
SIGNAL CRAYFISH AS DRIVERS OF FINE SEDIMENT DYNAMICS IN RIVERS: FIELD AND LABORATORY EVIDENCE
}

\section{Gemma L Harvey, Alexander J Henshaw, Tom P Moorhouse, Helen Holah, Nicholas J Clifford, David W Macdonald and Jonathan Grey}

\section{SHORT TITLE (70char):}

SIGNAL CRAYFISH AS DRIVERS OF FINE SEDIMENT DYNAMICS IN RIVERS

\begin{abstract}
(300words)
Despite increasing recognition of the potential of aquatic biota to act as 'geomorphic agents' and influence sediment dynamics in rivers, key knowledge gaps exist in relation to biotic drivers of fine sediment dynamics at microscales and particularly the role of invasive species. This paper explores the impacts of invasive signal crayfish on fine sediment dynamics (suspended sediment/ turbidity) at the patch scale through laboratory and field study. It was hypothesised that signal crayfish generate pulses of fine sediment mobilisation through burrowing and movement that are detectable in the flow field; and that such pulses may be more frequent during nocturnal periods when signal crayfish are known to be most active. Laboratory mesocosm experiments were used to explore crayfish impacts on suspended sediment concentrations for two treatments: clay banks and clay bed substrate. For the field study, high frequency near-bed and mid-flow turbidity time series from a lowland river with known high densities of signal crayfish were examined. Laboratory data demonstrate the direct influence of signal crayfish on mobilisation of pulses of fine sediment through burrowing into banks and fine bed material ${ }_{2}$ although there is not a clear nocturnal trend. Similar patterns of pulsed fine sediment mobilisation identified under field conditions follow a clear nocturnal trend and appear capable of driving an increase in 'ambient' turbidity levels. The findings indicate that signal crayfish may have the potential to influence suspended sediment yields, with implications for morphological change and the transfer of nutrients and contaminants. This is particularly important given spread of signal crayfish across Europe and their presence in extremely high densities in many catchments. Further process-based studies are required to develop a full understanding of impacts across a range of river styles.
\end{abstract}

\section{KEY WORDS (up to 5):}

\section{INTRODUCTION}

Fine sediment, comprising sand, silt and clay, accounts for the majority of total fluvial sediment flux, and has important implications for catchment water resource management, particularly since changes in fine sediment dynamics can modify sediment yields and initiate morphological adjustments downstream (Walling and Collins, 2008). Such changes may have implications for channel morphology and conveyance capacity, aquatic ecosystem health and chemical water quality. For instance, aggradation of fine sediments can degrade aquatic habitats, reducing survival rates of fish and aquatic invertebrates (Marks and Rutt, 1997; Heywood and Walling, 2006); and reduce flow conveyance, with the potential to increase flood risks (c.f. Lane et al., 2007). In addition, fine sediments play a significant role in the transport of both nutrients and pollutants within fluvial environments (Bowes et al., 2003; House, 2003; Carter et al., 2006), with implications for water quality.

Fine sediment dynamics can be classified into three domains with associated modes of explanation (Naden, 2010). At the catchment scale, fine sediment flux is determined primarily by the geomorphological characteristics of the fluvial system and the history of erosion and sediment transfer (e.g. Trimble, 1983). Time-scales of interest in determining catchment fine sediment fluxes may range from years to centuries, and catchment sediment budgets may be created from estimates of fine sediment storage and the apportionment of sediment sources (e.g. using fingerprinting techniques; Oldfield et al., 1979). At the reachscale of river systems, fine sediment flux is usually explored through measurement of 
suspended sediment concentrations (and/or water turbidity) and discharge. The amount of fine sediment transported by rivers typically follows a power law relationship with discharge (e.g. Bogardi, 1974), but often with large amounts of scatter in the relationship resulting from factors such as seasonal variability (e.g. associated with the growth and senescence of aquatic vegetation; Cotton et al., 2006) and hysteresis effects over the course of an individual hydrological event (Walling 1977; Williams, 1989). At small spatio-temporal scales in river channels (e.g. channel cross section; milliseconds to minutes), the physical factors that determine fine sediment dynamics are the physical properties of fine sediments and the high-frequency properties of the flow. Examination of such characteristics requires highfrequency sampling of water turbidity and flow velocities, and such studies have illustrated the role of turbulent flow structures in initiating short duration, high magnitude bursts of fine sediment transport (Lapointe, 1992; 1996).

Recent literature has also given increasing attention to the complexity introduced into sediment entrainment and transport processes by the presence of aquatic organisms acting as 'geomorphic agents' or 'ecosystem engineers' (Jones et al., 1994). This includes aquatic and riparian vegetation (e.g. Gurnell and Petts, 2006; Bertoldi et al., 2009; Gurnell et al., 2012), aquatic invertebrates (Statzner et al., 2003; Wharton et al., 2006; Johnson et al., 2009) and mammals (e.g. Wright et al., 2002). Within this context, the influence of aquatic organisms on fluvial sediment dynamics may be particularly pronounced for invasive species, which represent a disturbance to which the river system may not be resilient, ${ }_{2}$ and which may be present in-at very high densities (Harvey et al., 2011). Impacts associated with invasive species may also become more significant as a result of future climate change and habitat loss pressures, which may increase the susceptibility of natural communities to invasions (Macdonald and Burnham, 2010). Despite this, there remains a lack of studies exploring potential biotic drivers (including invasive species) of fine sediment dynamics within rivers. A sound understanding of the ways in which invasive aquatic biota influence fine sediment dynamics from the patch to the catchment scale of river systems is vital for catchment sediment budgeting and management efforts, but represents a new and underdeveloped research area.

This paper focuses on one particular invasive aquatic species, the signal crayfish (Pacifastacus leniusculus) which is endemic to North America, but has been introduced to over 20 countries in Europe since the 1960s (Lewis, 2002), including Britain where its has rapidly colonised river catchments since the mid-1970s (Holdich, 2000). Much of the research on invasive signal crayfish has, to date, focused on biotic interactions, including impacts on the-native white-clawed crayfish (Austropotamobius pallipes) populations, which have been devastated by the arrival and rapid spread of signals over the last few decades (Alderman et al., 1990; Holdich, 2003; Bubb et al., 2005). Studies have also highlighted further impacts on a range of biota:- cGrayfish are omnivorous feeders, leading to detrimental effects on macroinvertebrates and fish associated with a combination of direct predation and destruction of habitats such as aquatic macrophytes, which represent a further food source (Guan and Wiles, 1997; 1998; 1999; Crawford et al., 2006). In contrast, few studies have examined the potential impacts on the physical river environment of the replacement of native white-clawed crayfish with this larger and more aggressive species, despite the fact that signal crayfish may be present in very high densities - up to 20 individuals $\mathrm{m}^{-2}$-(Abrahamsson and Goldman, 1970; Bubb, 2004) $-\overline{-}$ and are known to burrow much more extensively than white-clawed crayfish (Lewis, 2002). This represents a significant gap in knowledge, particularly since there are currently no effective measures for control or mitigation available for signal crayfish (Holdich et al., 1999).

Crayfish are known to act as 'geomorphic agents', impacting directly upon the physical environment of river systems (Newton, 2010). This includes bioturbation of sediments through movements such as walking and tail flips (Statzner and Sagnes, 2008); alteration of bedform roughness and modifying bed material particle size distributions and particle 
consolidation (Statzner et al., 2000; 2003); changes in the composition of fine sediments associated with the processing of organic matter (Usio, 2000); and extensive burrowing into soft river banks which may increase bank erosion and associated increased inputs of fine sediments (Lewis, 2002). Much of this detailed research on sediment mobilisation, however, focuses on experimental laboratory streams and on coarser (gravel-sized) bed material. Reaches characterised by fine bed and bank material may in fact be more susceptible to these geomorphic impacts, and hence there is a great need for improved process understanding at local scales in order to inform up-scaling and assess the nature and extent of potential implications for catchment-level sediment management, water quality and physical habitat. A full review of the possible impacts across a range of scales, and their current evidence base is provided in Harvey et al. (2011).

This paper presents findings from combined field and laboratory work which aims to explore signal crayfish impacts on fine sediment dynamics at the patch scale. In particular, two hypotheses are tested:

1. Signal crayfish generate pulses of fine sediment mobilisation through their interactions with river bed and bank material (burrowing and movement) that are detectable in the flow.

2. The frequency of pulsed sediment mobilisation events is greater during nocturnal periods when crayfish in general, and signal crayfish in particular are known to be most active (Hill and Lodge, 1994; Lozan, 2000; Gherardi et al., 2001; Styrishave et al., 2007).

\section{RESEARCH DESIGN AND METHODS}

Research design

A combination of laboratory and field study was employed to address the research hypotheses. Laboratory mesocosm experiments focused on interactions with fine bed sediment and artificially created banks. Laboratory mesocosms provided controlled conditions under which detectable changes in suspended sediment concentration could be directly related to crayfish interacting with artificial banks and substrates constructed from fine sediments. This was designed to provide 'proof of concept' for impacts on fine sediment mobilisation. The field study identifies whether similar suspended sediment (turbidity) patterns are identifiable under field conditions, providing a preliminary indication of the realworld relevance of the process. Given the episodic nature of bank erosion processes (and burrowing activity) and hence the complexities of exploring bank erosion processes in the field, field experiments focused on crayfish interactions with bed material only for this study.

In both laboratory and field studies, turbidity was used to provide an indicator of suspended sediment concentrations. Turbidity is a measure of the degree to which light passing through a water body is scattered and/or absorbed by particulate matter held in suspension and has been used to indicate suspended sediment concentrations in a range of field applications (e.g. Clifford et al., 1995; Gippel, 1995; Brasington and Richards, 2000; Harvey and Clifford, 2010). The focus on turbidity rather than time-integrated suspended sediment sampling is appropriate in this application, since it allowed continuous high frequency sampling (Lapointe, 1992; Clifford and French, 1996) and minimised the disturbance to flow and fine sediments at sampling locations. Turbidity was recorded using Partech IR40 and/or IR100 infrared turbidity sensors connected to a Campbell Scientific CR10X data logger, recording data at a frequency of $5 \mathrm{~Hz}$. The $0-5 \mathrm{~mA}$ signal produced by the turbidity sensors is converted to a voltage by placing a resistor in the current loop (Clifford et al., 1995). The IR40 and IR100 have path lengths of $40 \mathrm{~mm}$ and $100 \mathrm{~mm}$, and suspended sediment concentration detection ranges of $0-200 \mathrm{mgl}^{-1}$ and $0-1500 \mathrm{mgl}^{-1}$, respectively.

While the relationship between turbidity and suspended sediment concentration is affected by particle size, shape and colour, it can be calibrated with respect to either in situ particles 
(Clifford et al., 1995) or Formazin Turbidity Units (FTU) using a formazin solution (HMSO, 1984). Calibration curves are generally s-shaped and can be described by linear relationships for a large part of the range. For the laboratory experiments, turbidity was converted to sediment concentration $\left(\mathrm{mgl}^{-1}\right)$ by calibration with suspended sediment samples collected across a range of concentrations during the experiments. Samples were filtered through $2.5 \mu \mathrm{nm}$ papers and dried at $100^{\circ} \mathrm{C}$ to obtain dry weight. Regression curves were fitted to the relationships between voltage output and suspended sediment concentration. For the field study, turbidity was converted to FTU through calibration with formazin solution across a range of concentrations. Regression curves were fitted to the relationships between voltage output and FTU.

\section{Laboratory mesocosms}

Laboratory experiments were conducted within replicate treatment and control mesocosm tanks $(0.24 \times 0.45 \times 0.3 \mathrm{~m})$ filled with $10 \mathrm{l}$ of tap water. There was no flow through the tanks so both treatment and control tanks were aerated using standard aquarium air stones and tubing and an AirBlow 100 pump unit. The tanks were maintained at $15^{\circ} \mathrm{C}$ under a fixed light regime of 12 hours light (07:00-19:00) followed by 12 hours of darkness (19:00-07:00). Artificial banks and substrates were prepared using bentonite clay. For the bank experiments, replicate artificial banks were created by moulding damp sediment and placing it under weights for several days to create solid clay blocks of a consistent volume $(0.08 \mathrm{x}$ $0.10 \times 20.5 \mathrm{~m})$ and shear strength $\left(0.05 \mathrm{~kg} / \mathrm{cm}^{3}\right.$; measured using a shear vane). Banks were held in place at each side of the tank using wooden panels. For bed substrate experiments, the base of each tank was covered with bentonite to a depth of $0.03 \mathrm{~m}$ and compressed under weights in the same ways as artificial banks. The substrate was covered with plastic sheeting as the tanks were filled to prevent disturbance of the sediment. Signal crayfish were identified and collected from field sites within the Greater London area. One mediumsized crayfish $(22.5-36 \mathrm{~mm})$ was placed into each treatment tank and no crayfish were present within the control tanks. Crayfish were not sexed but had both claws intact, and were frozen following the completion of the experiments. Turbidity sensors were positioned $10 \mathrm{~cm}$ above the bed in each of the control and treatment tanks. Figure 1a illustrates the experimental design.

\section{Field study}

High-frequency turbidity records were obtained from a site on the eastern fork of the River Windrush (UK grid reference SP 401 050; Figure 2) on 1 and 2 July 2009. The Windrush drains an area of $362.6 \mathrm{~km}^{2}$ from its source in Gloucestershire to its confluence with the River Thames at Newbridge. The majority of the catchment is underlain by pervious Oolitic limestone and land use is predominantly agricultural, although extensive gravel workings and the town of Witney (population 22,265) are prominent features of the lower valley. The mean annual rainfall in the catchment is $743 \mathrm{~mm}(1961-90)$ and the mean daily flow of the Windrush at Newbridge is $3.35 \mathrm{~m}^{3} \mathrm{~s}^{-1}$ (1950-2009). The Windrush has a large population of signal crayfish. The native white-clawed crayfish are no longer present in the majority of the catchment and are confined to its headwaters which have yet to be invaded by the signal crayfish. The field site forms part of a wider project by the Wildlife Conservation Research Unit, University of Oxford, researching signal crayfish movements, growth rates and removal strategies (Moorhouse and Macdonald 2011a, b, c)(Tom's papers) which provides quantitative data on signal crayfish densities in the study reach. Signal crayfish densities at the time of the study were extremely high: from the $500 \mathrm{~m}$ section surrounding the turbidity monitoring station: 6158 individual crayfish were captured from 35 traps set for a total of 24 nights between April and September 2009 (for further information see Moorhouse and Macdonald, 2010). Although a robust population estimate was not available for the study site, these figures demonstrate that the study reach contained a very large number of signal crayfish and population estimates from two nearby rivers equate to $>3000$ individuals per $100 \mathrm{~m}$ (Moorhouse and Macdonald, submitted2011a). 
Turbidity monitoring equipment was deployed for a period of 16 hours, encompassing approximately 9-nine hours of daylight and 7 seven hours of darkness between $5 \mathrm{pm}$ on $1 \mathrm{st}$ July 2009 and 9am on 2nd July 2009, incorporating the nocturnal period when signal crayfish are typically most active (Hill and Lodge, 1994; Lozan, 2000; Gherardi et al., 2001; Styrishave et al., 2007). Due to uncertainties associated with the expected field range of suspended sediment concentrations, two types of turbidity sensor with differing ranges (IR40C and IR100C) were mounted as a pair at 0.8 of the water depth from the surface in order to capture-near bed turbidity variations. A further IR40C sensor was mounted at 0.6 of the water depth from the surface to record mid-flow turbidity levels. The monitoring equipment was positioned within a 'glide' physical biotope unit (Bisson et al., 1981; Newson and Newson, 2000), characterised by homogeneous smooth boundary turbulent surface flow conditions and water depths, and fine bed material (sand and silt). Turbidity sensors were installed at a point in the channel cross section that was expected to be associated with high levels of crayfish movement: towards the bank, adjacent to overhanging marginal vegetation that provides cover (Jowett et al., 2008). Figure $1 \mathrm{~b}$ illustrates the experimental design.

Hydrological conditions were stable for the duration of the monitoring period: discharge and water depth at the monitoring location were $0.46 \mathrm{~m}^{3} \mathrm{~s}^{-1}$ and $0.7 \mathrm{~m}$ respectively and remained constant. Flow stage was low, reflecting the meteorological conditions encountered at the time of the study: maximum daytime temperatures exceeded $28^{\circ} \mathrm{C}$ and no rainfall was detected at Met Office operated rain gauges in the surrounding catchment for at least four days prior to the experimental period. Discharge records from a downstream gauging station at Newbridge, below the confluence of the eastern and western forks of the Windrush, confirm stationarity in flow conditions throughout the monitoring period (Figure 3). High frequency flow properties were sampled over the period of record on an approximately hourly basis in order to identify changes in turbulent bursting and event-driven boundary layer organisation (McQuivey, 1973; Clifford et al., 1993; Ashworth et al., 1996) which can result in short-term sediment suspension (Lapointe, 1992; 1996). High frequency flow measurements were taken immediately adjacent to turbidity sensors, in the near-bed region ( 0.8 of the flow depth from the surface), using a Sontek field $10 \mathrm{MHz}$ 3D Acoustic Doppler Velocimeter (ADV) sampling streamwise $(U)$, cross stream $(\mathrm{V})$ and vertical $(\mathrm{W})$ velocities at a frequency of $16 \mathrm{~Hz}$ for a sampling period of 5 minutes.

\section{Data analysis}

The first stage of analysis involved visual examination of calibrated turbidity traces to check for data quality issues and anomalies, and to identify scales of variation the data set and detrending requirements. For both field and laboratory data sets, shorter-duration pulsed turbidity events superimposed on longer-term trends were visually identifiable on time series plots. Turbidity pulses were identified and isolated from low magnitude trends in ambient turbidity in order to estimate the number of pulses, their duration and the maximum turbidity value achieved for each pulse. For laboratory data, it was possible to detrend time series using a moving average filter. For field data the low magnitude trend was more subtle relative to the magnitude of discrete turbidity pulses and detrending involved downweighting of high magnitude values to within the ambient turbidity range (as identified visually from timeplots; see Chatfield, 2004), followed by the fitting of 4th order polynomial regressions to time series. Turbidity residuals were derived from the low magnitude trends and downweighted values were reinstated within the time series to allow analysis of turbidity pulse characteristics. A conservative analytical regime was adopted, based on identification of an appropriate threshold value to delimit turbidity pulses. For field data the threshold was set so as to exceed the remaining variance in ambient turbidity (observed through visual inspection) in detrended turbidity time series (6 FTU; equal to approximately 1.5 times the ambient range). For laboratory time series, the same threshold value of 1.5 was set for turbidity residuals following detrending using the moving average filter. Events lasting less than 1 second (and hence consisting of 5 or less consecutive turbidity samples) were not included in the analysis for both field and laboratory time series so as to focus analysis on 
the more pronounced and clearly defined pulses. For the laboratory time series, where events were less discrete as a result of the non-circulatory nature of the tanks, turbidity events separated by less than 2 seconds were combined into a single event. The thresholds chosen will necessarily influence the estimated absolute number of events and their duration but allow comparability across data sets. Non-parametric Mann-Whitney $U$ tests were used to identify statistically significant differences between control and treatment laboratory time series, and between night and daylight hours in the field ambient turbidity data set.

For the field data set only, the character of pulsed turbidity events was explored further by classifying pulses by shape and magnitude through application of Principal Components Analysis (PCA) and Hierarchical Cluster Analysis (HCA). A combination of PCA and HCA was used to identify variations in event 'shape', and a second, separate HCA was used to identify variations in event 'magnitude'. The approach has been used by Hannah et al. (2000) to classify hydrographs. A varimax PCA was applied to a data matrix of N columns of pulses by $n$ rows of sequential turbidity values. In order to achieve a matrix of turbidity pulses with an equal number of rows for each pulse, events were artificially extended to the length of the longest duration pulse in the time series using the ambient turbidity threshold value. The process of applying PCA reduces the dimensionality of the data set and hence reduces the matrix of empirical turbidity response curves into a smaller number of generalised curves representing events of similar character. Nine Principal Components (PCs) with eigenvalues greater than 1 cumulatively explained $94 \%$ of the variance in the IR40C turbidity series. HCA (average linkage method) was then applied to the component loadings of these nine PCs in order to identify pulses of similar 'shape' (Hannah et al., 2000) and the number of clusters within the data set was identified from breaks in the dendrogram. The second process involved performing a separate HCA (Ward's method) on a set of variables used to describe the 'magnitude' characteristics for each event: mean turbidity; turbidity range; standard deviation of turbidity; and time to peak. In contrast to the method used by Hannah et al. (2000) standardisation to z-values was not necessary for the turbidity values since these were derived from a single detrended time series.

\section{RESULTS}

Visual inspection of laboratory and field time series

Replicate time series for the bank and substrate laboratory experiments are presented in Figure 4. For each of the two experiments, there is a clear distinction between control and treatment time series, with evidence of considerable mobilisation of sediment within the treatment tanks in the form of both shorter duration, higher magnitude 'pulses' of sediment mobilisation and/or lower magnitude cyclic increases and an overall trend of increasing suspended sediment concentration following the start of the experimental period. For the bank treatment, control traces show some fluctuations over time which reflects localised bank collapse as a result of saturation. This is negligible in relation to the treatment tanks, however, and Mann-Whitney $U$ tests confirm statistically significant differences between control and treatment pairs for both bank and bed experiments $(p<0.001)$. Further analysis focuses on treatment time series only.

Bank treatment time series show higher overall suspended sediment concentrations, greater prominence of shorter-duration fluctuations and greater similarity between runs compared to substrate time series. No clear nocturnal trend is apparent for either treatment, which may reflect the influence of introduction of the crayfish to a new environment on signal crayfish behaviour. There is, however, a trend towards a reduction in suspended sediment concentration following the end of the night-time period for some of the runs (notably for bank run 1 and substrate runs 1 and 2) although this is not consistent across the full data set. For the substrate treatment, time series show evidence of cyclic variations in crayfish activity and there is a considerable difference in the character of turbidity traces between runs. A large number of high magnitude, short duration pulses occur on one of the runs 
while the remaining two are characterised by a series of more prolonged, low magnitude increases in suspended sediment concentration.

These trends in suspended sediment concentration correspond with visual observation of crayfish behaviour in the two treatment tanks. Example still photographs and video clips are provided in Figure 5 and $X$ respectively. For substrate treatments, crayfish dug pits in corners of the tank in which they positioned themselves for periods of time (Figure $5 a$ and $b$ ). For bank treatments, crayfish created and inhabited burrows in the artificial banks (Figure $5 c$ and d) but the displacement of sediment through burrowing was combined with associated periodic, localised collapse of bank material which also mobilised sediment (Figure $5 e$ and f), contributing to suspended sediment concentrations.

Field turbidity time series derived from the near-bed and mid-flow sensors are presented in Figure 6 and reveal two key features. First, a large number of high magnitude turbidity pulses are detected in the near-bed region by both sensors. In contrast, the mid-flow sensor fails to detect these with the exception of one pulse which appears to have been detected by all three sensors. Second, there is a clear increase in the frequency of near-bed turbidity pulses between approximately 21:00 and 06:00, corresponding closely with the period of darkness between sunset $(21: 20)$ and sunrise (04:48). High frequency flow data presented in Figure 7 demonstrate stationarity in $U \mathrm{~V}$ and $\mathrm{W}$ velocity components throughout the sampling period in terms of both average velocity values and variation around the mean. This suggests that no significant changes in flow variability occurred during the sampling period, at either low or high frequencies, that would indicate a turbulence-induced change in pulsed turbidity events during the monitoring period.

\section{Pulsed turbidity events}

Discrete suspended sediment pulses occurring within the laboratory data sets are explored in Figure 8. The number of pulses varies between experimental runs even for the same treatment, again supporting the suggestion that crayfish behaviour varied between runs and exerted a considerable influence on the character of turbidity time series. Overall, the number of pulses was higher for the bank treatments (between 743 and 1941 pulses; accounting for between 7 and 10 hours of the record) relative to the substrate treatment (between 398 and 737 pulses; accounting for between 1 and 7 hours of the record). The higher number of pulses for the bank treatment reflects three factors. First, there was a greater potential for burrowing into the artificial banks relative to the bed substrate due to the greater depth and width of consolidated material. Second, the occurrence of sediment pulses in the bank treatment reflects the combined contribution of 'direct' impacts of burrowing activity transferring sediment into water column and the 'indirect' impacts associated with partial bank collapse. A small amount of bank collapse occurring under the control treatment suggests that saturation of artificial banks played a small role, but bank collapse was greatly accentuated by crayfish burrowing. Third, two of the substrate time series showed less evidence of high magnitude pulsed events, but instead cyclic variations in suspended concentrations. This correlates with observed crayfish behaviour in which activity tended to more restricted and concentrated in the corners of the tanks.

The number of pulses occurring in each hour of the monitoring period varies between runs and ranges from zero to 300 . There is no clear nocturnal trend in the number of pulsed events as identified previously from time plots, although both bank and substrate experiments show some evidence of an enhanced number of pulses between 00:00 and 03:00 which then declines towards the end of the record at 12:00. The vast majority of pulses are short in duration (for bank treatments median $=3.75 \mathrm{~s}$ and upper quartile $=8.75 \mathrm{~s}$; for substrate experiments median $=3.25 \mathrm{~s}$ and upper quartile $=10.75)$, and with maximum turbidity values up to $5 \mathrm{mgl}^{-1}$ (for bank treatments median $3.75 \mathrm{mgl}^{-1}$; upper quartile $=5.14$ $\mathrm{mgl}^{-1}$; for substrate treatments median $=3.95 \mathrm{mgl}^{-1}$; upper quartile $=5.40 \mathrm{mgl}^{-1}$ ). A smaller number of pulses endure for over 1 minute, up to a maximum of 20 minutes, reflecting 
periods of more sustained crayfish activity. Likewise a small number of short duration, high magnitude pulses with peak turbidity values exceeding $100 \mathrm{mgl}^{-1}$ occur in the record for both treatments, indicating sediment mobilisation events closer to the turbidity sensor. However, the pulse duration and turbidity characteristics for the laboratory time series will be strongly controlled by tank hydraulics, and the non-circulatory nature of the tanks means that both pulse duration and turbidity levels are likely to be considerably greater than for crayfishinduced sediment mobilisation events occurring under field conditions. As a result, pulse characteristics for laboratory data were not analysed further.

Figure 9 plots characteristics for each pulsed turbidity event identified on the IR40 near-bed sensor for the field turbidity series. Since several high magnitude turbidity pulses detected by the IR100C sensor resulted in the readings outside of the sensor range, and only one pulse was detected on the mid-flow IR40C sensor, turbidity pulse analysis focuses on the near-bed IR40C sensor only for field data. In total, 88 events were identified for the IR40C near-bed sensor, an order of magnitude below the values identified in laboratory data. This was expected given the small surface area of the tank and the absence of flow to advect and diffuse sediment plumes. One pulse was removed from the time series for the IR $40 \mathrm{C}$ since it was over 15 minutes in length (compared to $<40 \mathrm{~s}$ for all other events) and of similar magnitude throughout. This was considered to represent a temporary sensor obstruction such as a piece of organic debris, rather than a discrete sediment suspension event.

Figure 9a illustrates a clear nocturnal trend in pulse frequency for the field data set: no pulses are detected between 17:00 and 19:00 and the number of pulsed events per hour then increases from 1 between 19:00 and 19:59 to a peak of 23 between 23:00 and 23:59, decreasing to zero by 07:00 the following day. Pulse duration and maximum turbidity reveal a large degree of scatter through the period of record (Figure $9 b$ and $c$ ), although there appears to be a tendency towards higher variability in pulse duration/ magnitude towards the mid-point of the night-time period. The relationship between pulse duration and magnitude (Figure 8d) is approximately linear, i.e. the longest duration pulses are mostly associated with the highest magnitude maximum turbidity values. The majority of pulses are associated with durations between $1 \mathrm{~s}$ and $15 \mathrm{~s}$ and maximum turbidity values up to $1500 \mathrm{FTU}$, with a smaller cluster of much longer duration events up to a maximum of $37 \mathrm{~s}$ and with a maximum turbidity up to 2600 FTU.

Figure 10 plots turbidity time series for individual pulses classified according to the shapemagnitude clusters derived from PCA and HCA. In total, eight pulse 'shape' clusters $(A-H)$ and three pulse 'magnitude' clusters (low, intermediate, high) were identified. Clusters $A$ and $B$ contain the lowest magnitude and shortest duration pulses; these pulse shapes are associated only with the lowest 'magnitude' cluster. The pulses in cluster B have a longer lag time, higher overall event magnitude and lower level of negative skewing relative to cluster $A$. The shapes of pulses in clusters $C, D$ and $E$ are more complex than $A$ and $B$, and demonstrate intermediate durations and variable magnitudes. Most pulses within these clusters show a lag in peak turbidity of up to 7 seconds from the onset of the event. Clusters $\mathrm{F}, \mathrm{G}$, and $\mathrm{H}$ only contain 3,1 and 2 pulses respectively and are therefore plotted together for brevity. Together, they comprise longer duration pulses with long lags and multiple peaks. Clusters $E, F$ and $G$ all contain pulses in which a secondary peak occurs following a delay of between 15 and $30 \mathrm{~s}$ from the onset of the pulse. These secondary peaks could represent a new, potentially unrelated turbidity event but since there is not a complete return to ambient turbidity, these pulses are treated as an individual event for the purposes of this analysis. Given their close proximity in time and similarity in shape, it is possible that these pulses may represent a repetition of the same phenomenon occurring in the same spatial location. The occurrence of the different shape-magnitude pulse clusters varies throughout the period of record. Events belonging to cluster A were distributed throughout the period between 19:00 and 06:00 but the period of greatest variability in cluster type occurs between 22:00 
and 03:00, and almost all of the events associated with clusters $B, C, D$ and $E, G$ and $H$ fall within this period.

\begin{abstract}
Nocturnal trend in ambient turbidity for field data
Figure 11 plots average hourly turbidity values for the low magnitude trend in 'ambient' turbidity in field data (i.e. following the removal of discrete high magnitude turbidity pulses) for all three sensors. An abrupt increase in turbidity at around 19:50 which lasted for approximately 50 minutes on the IR $100 \mathrm{C}$ sensor only was considered to represent an anomalous event associated with a piece of debris becoming trapped around the sensor and was therefore excluded from the 'ambient' data set. For the near-bed sensors there is a clear nocturnal trend associated with an increase in ambient turbidity from approximately 21:00 up to around 02:00, which then recedes to approximately the original level by around 08:00. This trend is more pronounced for the IR100C which is more sensitive at the lower part of the turbidity range (Henshaw, 2009). The mid-flow IR40C sensor curve demonstrates a slightly different character from the near-bed sensor curves, rising from around 21:00 until reaching a peak around $04: 00$, but fails to return to the original level during the period of record, remaining approximately 5 FTU higher than the starting turbidity value. In order to test the statistical significance of these nocturnal variations, Mann Whitney $U$ tests were performed on daylight and night-time groupings of minute-averaged ambient turbidity values for each of the three turbidity sensors according to the timing of sunset and sunrise. This confirmed statistically significant differences in the mean daylight and night-time ambient turbidity values for each of the three sensors $(p<0.001)$.
\end{abstract}

\section{DISCUSSION}

The analysis of high frequency suspended sediment and turbidity time series from laboratory and field studies revealed a number of interesting features that support the research hypotheses. First, laboratory data demonstrate the ability of signal crayfish to mobilise fine sediment through different types of movement, creating pulsed sediment suspension events of varying magnitude and duration. These pulsed events are sufficient to drive a statistically significant increase in suspended sediment concentrations in still-water tanks. For bank treatments, crayfish were observed to burrow extensively into artificial clay banks, consistent with field observations of dense networks of burrows in invaded habitats (Guan, 1994; Holdich et al., 1999). The burrowing action caused direct mobilisation of fine sediments into the water column, creating pulsed suspension events. This was combined with crayfish movements across destabilised material and the periodic partial collapse of bank material which was enhanced by burrowing activity. For substrate treatments, pulsed suspension events were associated with crayfish movements across the bed and the digging of pits in the corner of the tanks. Other species of crayfish have also been observed to mobilise fine sediment during walking, foraging and swimming (e.g. Paranephrops planifrons: Parastacidae; Parkyn et al., 1997) and signal crayfish are known to be capable of mobilising larger gravel-sized sediment particles (Johnson et al., 2010). Signal cravfishs have also been shown to create pit and mound features in coarse sediment beds under laboratory conditions (Johnson et al., 2010), similar to those observed in fine sediment beds for this study. This may partly reflect a lack of cover in substrate tanks, leading to the crayfish adopting a defensive position. While there is no clear nocturnal trend in laboratory data, there was a suggestion of an increase in events between 00:00 and 03:00 and a decline towards the end of the night-time period in several experimental runs. (which FIG and give some indicative statistics, perhaps - e.g. in light periods there were $x$ events per hour on average, and in the period 0:00-03:00 there were y events per hour)??

The laboratory experiments provide clear evidence of the ability of signal crayfish to mobilise fine sediment under controlled conditions. However, relationships between crayfish behaviour and suspended sediment concentrations for laboratory experiments will be greatly influenced by both the hydraulic conditions of the tanks and the altered behaviour of the crayfish as a result of their placement in a different environment. Tanks were not
Formatted: Highlight 
recirculating, meaning that pulsed suspension events were not subject to advection and diffusion processes that would be significant under field conditions (Rutherford, 1994). This limits the potential for detailed analysis and interpretation of sediment pulse characteristics for laboratory time series. The lack of cover, food sources, competition and predation as well as artificial lighting and temperature control will have influenced crayfish behaviour during the experimental period. In particular the absence of diurnal predatory fish such as brown trout (Salmo trutta) and perch (Perca fluviatilis) - which in addition to other diurnal predators such as otters (Lutra lutra) and American mink (Neovision vision), are major predators of signal crayfish (Lewis 2002 ) - could partially explain the lack of the expected clear nocturnal trend under laboratory conditions. Shifts towards nocturnal activity in freshwater vertebrates have been interpreted as mechanisms to reduce the risk of predation (Fraser et al., 1993, 1995); for example juvenile fish are known to reduce activity in the presence of predators, a trait which is lost under captive conditions (Alvarez and Nicieza 2003). Similarly, crayfish are known to cease or curtail various behaviours in the presence of conspecific alarm odours (Hazlett, 2003), and in the absence of such odours (as would be the case in laboratory conditions) it is likely that signal crayfish would continue diurnal activities (e.g. Lozan, 2000). In addition, the introduction of crayfish to the new environment of the treatment tanks appeared to generate a period of initial exploration activity that led to increases in sediment suspension that could not be differentiated from any nocturnallydriven variations.

The field data set reveals pulsed turbidity events similar to those identified in laboratory data. These occur in the near-bed region and are detected by two separate sensors, but similar pulses are not detected in the mid-flow region at the same location. Fewer pulses are identified in the field time series relative to laboratory data. This was expected, given the small surface area of laboratory mesocosms and the influence of advection and diffusion processes under field conditions. Importantly, turbidity pulses identified on field time series appear tightly constrained to the period of darkness between sunset and sunrise. The pulsed events vary in duration, magnitude and 'shape' but can be grouped statistically into distinct clusters of similar magnitude and shape characteristics. There is a notable lack of short duration $(<5 \mathrm{~s})$ high magnitude observations characteristic of turbulence-induced sediment suspension events (McQuivey 1973; French and Clifford, 1992; Lapointe, 1996; Roy et al., 1996; Buffin-Belanger and Roy, 2005), and few extended duration (>15 s) events. The turbidity pulses are most frequent and most varied in their characteristics towards the mid-point of night-time period. These temporal trends correlate with known nocturnal increases in signal crayfish activity including movement, burrowing, fighting and feeding (Flint, 1977; Guan and Wiles, 1998; Lozan, 2000; Styrishave et al., 2007).

Observational data on crayfish activity during the monitoring period are not available for the field study, limiting direct process inference. However, the known behavioural characteristics of signal crayfish, combined with their presence in extremely high densities at the field site-(Tom's papers)_(Moorhouse and Macdonald 2011a, b, c), and the similar features identified in laboratory data sets, support the suggestion that they could be responsible for the observed trends in field data. Importantly, the turbidity increases are not explained by temporal variations in high frequency velocity characteristics, and seem independent of either discharge variations or possible enhanced supply from catchment runoff events in the immediate past. Additionally, the turbidity increases are more marked near to the river bed, indicating a local origin, and the nocturnal pattern observed in field data, with clear onset and cessation about the night time hours implies a causal or generating mechanism which is biological rather than physical in origin. The data also complement previous research that links bioturbation by the American red swamp crayfish (Procambarus clarkii) with increased suspended solids and dissolved nutrients in a wetland enclosure study (Angeler et al., 2001) and unpublished video capture of signal crayfish mobilising fine sediment plumes on the River Lark, UK (Roberts, 2012).

Formatted: Font: Italic

Formatted: Font: Italic

Formatted: Font: Italic 
The occurrence of pulsed turbidity events within the nocturnal period in field time series corresponds with a statistically significant increase in 'ambient' turbidity values (i.e. excluding pulses) in the near-bed region for the same period. Furthermore, a statistically significant increase in ambient turbidity is also recorded in the mid-flow region which appears timelagged relative to the near-bed trends. These data suggest a combined effect of localised turbidity events occurring both within the immediate vicinity of the sensors and upstream that is sufficient to drive a statistically significant increase in ambient turbidity both at the bed and also in the mid-flow region. The difference between the near-bed and mid-flow trends could reflect the cumulative effects of crayfish activity upstream and the diffusion and downstream advection of mobilised sediments which may have a time-lagged influence in the mid-flow region.

The combined field and laboratory approach taken in this paper was designed to overcome some of the extreme practical difficulties associated with process-based research at the geomorphology-ecology interface. For this study, laboratory experimentation provides a controlled environment for a proof of concept study that identifies detectable pulsed sediment suspension events of varying character that can be directly attributed to crayfish interacting with bed and bank material through movement and burrowing. However, crayfish behaviour will be influenced by the artificial surroundings of the laboratory ${ }_{2}$ and the nonrecirculatory nature of the tanks does not provide an accurate description of the character and significance of the pulsed mobilisation events under field conditions. Observational evidence is much more difficult to secure in the field as a result of a number of practical constraints, notably the need to isolate hydrological and hydraulic influences, maintenance, power and data storage constraints of field equipment, and the nocturnal behaviour of signal crayfish. In this case the field data set complements the laboratory data set by identifying similar pulsed sediment suspension features in a reach with extremely high densities of crayfish. This suggests real world significance, with the potential to drive an overall increase in turbidity levels and hence influence sediment dynamics at larger spatio-temporal scales (Harvey et al., 2011). While the signal crayfish is of particular interest due to its relatively large body size and aggressive nature, other invasive species of crayfish are also known to burrow into river banks (e.g. American red swamp crayfish Procambarus clarkii and spinycheeked crayfish Orconectes limosus) and hence may have similar impacts upon mobilisation of fine sediment from the river bed and banks.

\section{CONCLUSION}

This paper presents findings from combined field and laboratory work which illustrate signal crayfish impacts on fine sediment dynamics at the patch scale of river systems. Signal crayfish are shown to generate pulses of fine sediment mobilisation through their interactions with river bed and bank material (burrowing and movement) that create detectable changes in suspended sediment concentrations under controlled conditions. Field data suggest these changes may: (i) be significant at patch scales in river systems and (ii) follow a nocturnal trend. Whilst similar activities and associated sediment disturbances could be associated with native species, the larger body size and more aggressive nature of the signal crayfish, and its presence in many invaded catchments in extremely high densities, may lead to more significant sediment disturbance compared to that which may be expected for native species. Furthermore, signal crayfish are known to burrow much more extensively in invaded environments relative to both their native range and to other species such as the UK's native white-clawed crayfish.

If the impacts of signal crayfish on fine sediment mobilisation and transport become significant in specific reaches and/or for certain periods of time, downstream impacts could include morphological change, increased turbidity levels, and the mobilisation and transport of sediments and sediment-associated nutrients, seeds and plant propagules and contaminants. Such impacts could have detrimental effects for the ecological status of water bodies, and for flood risk through changes in conveyance capacity. Further process-based 
studies are required to develop a full understanding of relationships between fine sediment mobilisation and transport associated with various mechanistic abilities of crayfish; relationships between impact and body size; the influence of additional habitat-related variables such as food sources and refugia; temporal variations in activity levels including seasonal as well as diurnal; and the nature and scale of potential impacts across a range of river styles.

\section{ACKNOWLEDGEMENTS}

The research was supported by a British Society for Geomorphology Research Grant ('Field evidence for signal crayfish impacts on fine sediment dynamics in a lowland river'). Tom Moorhouse was funded by the Esmée Fairbairn Foundation, and Alex Henshaw was in receipt of an EPSRC PhD Plus Fellowship (EP/P5011431/1) at the University of Nottingham.

\section{LIST OF FIGURES}

Figure 1 Experimental design for laboratory mesocosm experiments and field study: (a) mesocosm tanks with artificial clay banks; (b) mescosm tanks with artificial clay substrate; (c) control and treatment tanks; and (d) photography of monitoring location at the field site on the River Windrush with diagram to show the equipment set-up.

Figure 2 Map showing the location of the field study site on the River Windrush, Oxfordshire, UK.

Figure 3 Time series of 15-minute discharge data for the River Windrush at Newbridge during the monitoring period, showing long-term flow percentiles. Source: Environment Agency.

Figure 4 Suspended sediment concentration time series for laboratory mesocosm experiments, showing each of the three runs for (a) bank treatments; and (b) substrate treatments.

Figure 5 Photographs illustrating key crayfish interactions with bank and bed material observed during the laboratory mescosm experiments: (a) crayfish digging a pit in the left corner of the tank; (b) crayfish digging a pit in the right corner of the tank, with a previously created pit visible in the left corner; (c) burrow visible in the artificial bank; (d) partial collapse of bank following extensive burrowing. (e) and (f) show the artificial bank treatment before the start of the experiment, and following removal of the crayfish at the end of the monitoring period.

Figure 6 Turbidity time series for: (a) IR40C near-bed; (b) IR100C near-bed; and (c) IR40C mid-flow. The dotted line in (b) represents the upper limit of the IR100C range - turbidity values which meet the line indicate turbidity levels in excess of 2000 FTU.

Figure 7 High frequency velocity data for the field site on the River Windrush. Box-plots show median, interquartile range (boxes), 1.5 times the interquartile range (whiskers) and outliers (points) for streamwise (U), cross stream (V) and vertical (W) velocities.

Figure 8 Hourly time plots for pulsed turbidity 'events' identified in the laboratory suspended sediment concentration time series, showing: number of pulses per hour (minimum, maximum, median across runs) for (a) bank treatments and (b) substrate treatments; and the duration and maximum turbidity of individual pulses for (c) bank treatments and (d) substrate treatments. 
Figure 9 Characteristics of pulsed turbidity 'events' identified in the field turbidity time series for the IR40C near-bed sensor, showing: (a) number of pulses per hour of the record; (b) duration and (c) maximum turbidity of pulses according to their position in the record; and (d) the relationship between pulse duration and maximum turbidity.

Figure 10 Event time-plots presented in shape-magnitude clusters. For (a) to (e), each plot represents a 'shape' cluster ( $A$ - E respectively), and within each plot solid lines represent low magnitude, dashed lines intermediate magnitude and dotted lines high magnitude events (identified from the magnitude HCA). For (f), a series of small clusters are plotted together for brevity, with a separate legend.

Figure 11 Trends in ambient turbidity, following removal of short-term pulsed events for: (a) IR40C near-bed sensor; (b) IR100C near-bed sensor; and (c) IR40C mid-flow sensor. Vertical dotted lines mark the timing of sunset and sunrise.

\section{REFERENCES}

Abrahamsson SAA and Goldman CR (1970) Distribution, density and production of the crayfish Pacifastacus leniusculus Dana in Lake Tahoe, California - Nevada. Oikos 21: 8391.

Alvarez, D., Nicieza, A., 2003. Predator avoidance behaviour in wild and hatchery-reared brown trout: the role of experience and domestication. Journal of Fish Biology 63: 15651577.

Alderman DJ, Holdich DM, and Reeve I. (1990) Signal crayfish as vectors in crayfish plague in Britain. Aquaculture 86: 3-6.

Ashworth PJ, Bennett SJ, Best JL and McLelland SJ. (1996) Coherent flow structures in open channels. John Wiley and Sons Ltd, Chichester.

Bertoldi W, Gurnell AM and Drake NA (2011) The topographic signature of vegetation development along a braided river: results of a combined analysis of airborne lidar, colour air photographs and ground measurements. Water Resources Research 47: W06525

Bisson PA, Nielson JL, Palson RA, Grove LE. (1981) A system of naming habitat in small streams, with examples of habitat utilization by salmonids during low streamfl ow. In Acquisition and Utilization of Aquatic Habitat Inventory Information: Proceedings of a Symposium. American Fisheries Society Western Division: Bethesda, MD.

Bogardi J. (1974) Sediment Transport in Alluvial Streams. Akadémiai Kiadô, Budapest

Bowes MJ, House, WA, and Hodgkinson, RA. (2003) Phosphorous dynamics along a river continuum. Science of the Total Environment 313: 199-212.

Brasington J and Richards KS. (2000) Turbidity and suspended sediment dynamics in the Nepal Middle Hills. Hydrological Processes 14: 2259-2274.

Bubb DH, Thom TJ, and Lucas MJ (2004) Movement and dispersal of the invasive signal crayfish Pacifastacus leniusculus in upland rivers. Freshwater Biology 49: 357-368.

Bubb DH, Thom TJ, and Lucas MC (2005) The within catchment invasion of the nonindigenous signal crayfish (Dana) in upland rivers. Bulletin Francais de Peche et de Pisciculture 376-377: 665-673. 
Buffin-Belanger T and Roy AG. (2005) $1 \mathrm{~min}$ in the life of a river: selecting the optimal record length for the measurement of turbulence in fluvial boundary layers. Geomorphology 68: 7794.

Carter J, Walling DE, Owens PN and Leeks GJL. (2006) Spatial and temporal variability in the concentration and speciation of metals in suspended sediment transported by the River Aire, Yorkshire, UK. Hydrological Processes 20: 3007-3027.

Chatfield C. (2004) The Analysis of Time Series: An Introduction. CRC Press LLC: Boca Raton, Florida.

Clifford NJ, French JR and Hardisty J. (1993) Turbulence: Perspectives on Flow and Sediment Transport. Chichester, John Wiley and Sons Ltd.

Clifford NJ, Richards KS, Brown RA, Lane SN. (1995) Laboratory and field assessment of an infrared turbidity probe and its response to particle size and variation in suspended sediment concentration. Hydrological Sciences Journal 40(6): 771-791.

Clifford NJ and French JR. (1996) Criteria for suspended sediment monitoring in river environments: field evaluation of contrasting turbidity sensor types using simulated sediment transport events. In Maxwell WHC, Preul HC and Stout GE (eds.) Proceedings Rivertech96: 1st International Conference on New/emerging Concepts for Rivers: 754-761.

Cotton JA, Wharton G, Bass JAB, Heppell CM and Wotton RS. (2006) Plant-water-sediment interactions in lowland permeable streams: investigating the effect of seasonal changes in vegetation cover on flow patterns and sediment accumulation. Geomorphology 77: 320-334.

Crawford L, Yeomans WE, and Adams CE (2006) The impact of introduced signal crayfish Pacifastacus leniusculus on stream invertebrate communities. Aquatic Conservation: Marine and Freshwater Ecosystems 16: 611-621.

Flint RW. (1977) Seasonal activity, migration and distribution of crayfish, Pacifastacus leniusculus, in Lake Tahoe. American Midland Naturalist 97: 280-292.

Fraser, N. H. C., Metcalfe, N. B. \& Thorpe, J. E. (1993). Temperature-dependent switch between diurnal and nocturnal foraging in salmon. Proceedings of the Royal Society of London, Series B 252: 135-139.

Fraser, N. H. C., Heggenes, J., Metcalfe, N. B. \& Thorpe, J. E. (1995). Low summer temperatures cause juvenile Atlantic salmon to become nocturnal. Canadian Journal of Zoology 73: 446-451

French JR and Clifford NJ. (1992) Characteristics and "Event-Structure" of near-bed turbulence in a macrotidal saltmarsh environment. Estuarine, Coastal and Shelf Science 34: 49-69.

Gherardi F, Renai B and Corti C. (2001) Crayfish predation on tadpoles: a comparison between a native (Austropotamobius pallipes) and an alien species (Procambarus clarkii). Bulletin Francais de la Peche et de la Pisciculture 361: 659-668.

Gippel CJ (1995) Potential of turbidity monitoring for measuring the transport of suspended solids in streams. Hydrological Processes 9: 83-97. 
Guan RZ and Wiles PR (1997) Ecological impact of introduced crayfish on benthic fishes in a British lowland river. Conservation Biology 11: 641-647.

Guan RZ and Wiles PR. (1998) Feeding ecology of the signal crayfish Pacifastacus leniusculus in a British lowland river. Aquaculture 169: 177-163.

Gurnell AM and Petts GE. (2006) Trees as riparian engineers: the Tagliamento River, Italy. Earth Surface Processes and Landforms 31: 1558-1574.

Gurnell AM, Bertoldi W and Corenblit D. (2012) Changing river channels: the roles of hydrological processes, plants and pioneer fluvial landforms. Earth Science Reviews 111: 129-141.

Hannah DM, Smith BPG, Gurnell AM and McGregor GR. (2000) An approach to hydrograph classification. Hydrological Processes 14: 317-338.

Harvey GL and Clifford NJ. (2009) Microscale hydrodynamics and coherent flow structures in rivers: Implications for the characterization of physical habitat. River Research and Applications 25: 160-180.

Harvey GL and Clifford NJ. (2010) Experimental field assessment of suspended sediment pathways for characterising hydraulic habitat. Earth Surface Processes and Landforms 35: 600-610.

Harvey GL, Moorhouse TP, Clifford NJ, Henshaw AJ, Johnson MF, Macdonald DW, Reid I and Rice SP. (2011) Evaluating the role of invasive aquatic species as drivers of fine sediment-related river management problems: the case of the signal crayfish (Pacifastacus leniusculus). Progress in Physical Geography 35: 517-533.

Hazlett, B.A., 2003. The effects of starvation on crayfish responses to alarm odor. Ethology 109: 587-592.

Henshaw AJ. (2009) Impacts of land use changes and land management practices on upland catchment sediment dynamics: Pontbren, mid-Wales. Unpublished PhD thesis. University of Nottingham.

Heywood MJT and Walling DE. (2006) The sedimentation of salmonid spawning gravels in the Hampshire Avon catchment, UK: implications for the dissolved oxygen content of intragravel water and embryo survival. Hydrological Processes 21: 770-788.

Hill AM and Lodge DM. (1994) Diel changes in resource demand - competition an predation in species replacement among crayfishes. Ecology 75: 2118-2126.

Holdich DM, Rogers WD and Reynolds JD. (1999) Native and alien crayfish in the British Isles. In: Gherardi F and Holdich DM.(Eds.) Crayfish in Europe as alien species: how to make the best of a bad situation? 221-236. Balkema, Rotterdam.

Holdich DM. (2000) The Development of Ecological Requirements to inform the Production of Conservation Objectives for white-clawed crayfish. English Nature, Peterborough.

House WA. (2003) Geochemical cycling of phosphorous in rivers. Applied Geochemistry 18: 739-748. 
HMSO (1984) Methods for the examination of waters and associated materials: Colour and turbidity of waters - 1981 Tentative methods. HMSO, London.

Johnson MF, Reid I, Rice SP and Wood PJ (2009) Stabilization of fine-gravels by netspinning caddisfly larvae. Earth Surface Processes and Landforms 34: 413 - 423.

Johnson MF, Rice SP and Reid I (2010) Topographic disturbance of subaqueous gravels by signal crayfish (Pacifastacus leniusculus). Geomorphology 123: 269-278.

Jones CG, Lawton JH, and Shachak M (1994) Organisms as ecosystem engineers. Oikos 69: 373-386.

Jowett IG, Parkyn SM and Richardson J. (2008) Habitat characteristics of crayfish (Paranephrops planifrons) in New Zealand streams using generalized additive models (GAMs). Hydrobiologia 596: $353-365$

Lane SN, Tayefi V Reid SC, Yu D, Hardy RJ. (2007) Interactions between sediment delivery, channel change, climate change and flood risk in a temperate upland environment. Earth Surface Processes and Landforms 32: 429-446

Lapointe M. (1992) Burst-like sediment suspension events in a sand bed river. Earth Surface Processes and Landforms 17:253-2970.

Lapointe MF. (1996) Frequency spectra and intermittency of the turbulent suspension process in a sand- bed river. Sedimentology 43: 439-449.

Lewis SD. (2002) Pacifastacus Biology of freshwater crayfish. In: Holdich DM. (Ed.) Biology of Freshwater Crayfish: 511-540. Blackwell, Oxford.

Lozan JL. (2000) On the threat to the European crayfish: A contribution with the study of the activity behaviour of four crayfish species (Decapoda: Astacidae). Limnologica 30: 156-161.

Macdonald D and Burnham D. (2010) The state of Britain's mammals: a focus on invasive species. People's Trust for Endangered Species: London. ISBN 0-9545711-5-0.

Marks SD and Rutt GP. (1997) Fluvial sediment inputs to upland gravel bed rivers draining forested catchments: potential ecological impacts. Hydrology and Earth System Sciences 1 : 499-508.

McQuivey RS. (1973) Summary of turbulence data from rivers, conveyance channels and laboratory flumes. United States Geological Survey Professional Paper, 802B.

Moorhouse, T.P., Macdonald, D.W. (2011a). The effect of manual removal on movement distances in populations of signal crayfish (Pacifastacus leniusculus). Freshwater Biologv 56 : 2370-2377.

Moorhouse, T.P., Macdonald, D.W. (2011b). The effect of removal by trapping on body condition in populations of signal crayfish. Biological Conservation.144: 1826-1831.

Moorhouse, T.P., Macdonald, D.W., (2011c). Immigration rates of signal crayfish (Pacifastacus leniusculus) in response to manual control measures. Freshwater Biology 56 993-1001.

Formatted: Font: Italic
Formatted: Font: Italic
Formatted: Font: Bold
Formatted: Font: Italic
Formatted: Font: Bold
Formatted: Font: Italic
Formatted: Font: Bold




\begin{abstract}
Moorhouse TP and Macdonald DW. (2010) Immigration rates of signal crayfish (Pacifastacus leniusculus) in response to manual control measures. Freshwater Biology DO|: $10.1111 / \mathrm{j} .1365-2427.2010 .02528 \times x$
\end{abstract}

Moorhouse TP and Macdonald DW. (submitted) The effect of manual removal on movement distances in populations of signal crayfish (Pacifastacus leniusculus).

Naden PS. (2010) The fine-sediment cascade. In: Burt T and Allison R. (eds) Sediment Cascades. Wiley-Blackwell, Chicester.

Newson MD and Newson CL. (2000) Geomorphology, ecology and river channel habitat; mesoscale approaches to basin-scale challenges. Progress in Physical Geography 24(2): 195-217.

Newton A. (2010) Geomorphology: Crayfish at work. Nature Geoscience 3: 592.

Oldfield F, Rummery TA, Thompson R and Walling DE. (1979) Identification of suspended sediment sources by means of magnetic measurements: some preliminary results. Water Resources Research 15: 211-218.

Parkyn SM, Rabeni CF, and Collier KJ (1997) Effects of crayfish (Paranephrops planifrons: Parastacidae) on in-stream processes and benthic faunas: A density manipulation experiment. New Zealand Journal of Marine and Freshwater Research 31: 685-692.

Roy AG, Buffin-Bélanger T and Deland S. (1996) Scales of turbulent coherent flow structures in a gravel-bed river. In: Ashworth P J, Bennett SJ, Best JL and McLelland SJ (eds.) Coherent Flow Structures in Open Channels, Chichester, John Wiley and Sons Ltd pp. 147-164.

Rutherford JC. (1994) River Mixing. John Wiley \& Sons: Chichester.

Statzner B, Fievet E, Champagne JY, Morel R and Herouin E. (2000) Crayfish as geomorphic agents and ecosystem engineers: Biological behavior affects sand and gravel erosion in experimental streams. Limnology and Oceanography 45: 1030-1040.

Statzner B, Peltret O and Tomanova S. (2003) Crayfish as geomorphic agents and ecosystem engineers: effect of a biomass gradient on baseflow and flood-induced transport of gravel and sand in experimental streams. Freshwater Biology 48: 147-163.

Statzner B and Sagnes P. (2008) Crayfish and fish as bioturbators of streambed sediments: Assessing joint effects of species with different mechanistic abilities. Geomorphology 93: 267-287.

Styrishave B, Bojsen BH, Witthofft $\mathrm{H}$ and Andersen O. (2007) Diurnal variations in physiology and behaviour of the noble crayfish Astacus astacus and the signal crayfish Pacifastacus leniusculus. Marine and Freshwater Behaviour and Physiology 40: 63-77.

Trimble SW. (1983) A sediment budget for Coon Creek Basin in the Driftless area, Wisconsin, 1853-1977. American Journal of Science 283: 454-474.

Usio N (2000) Effects of crayfish on leaf processing and invertebrate colonisation of leaves in a headwater stream: decoupling of a trophic cascade. Oecologia 124: 608-617. 
Walling DE. (1977) Limitation of the rating curve technique for estimating suspended sediment loads, with particular reference to British rivers. In: Erosion and Solid Matter Transport in Inland Waters (Proc. Paris Symp., July 1977), IAHS Publ. no. 122, 34-48.

Walling DE and Collins AL. (2008) The catchment sediment budget as a management tool. Environmental Science and Policy 11: 136-143.

Wharton G, Cotton JA, Wotton RS, Bass JAB, Heppell CM, Trimmer M, Sanders IA and Warren L. (2006) Macrophytes and suspension-feeding invertebrates modify flows and fine sediments in the Frome and Piddle catchments, Dorset (UK). Journal of Hydrology 330: 171-184.

Williams GP. (1989) Sediment concentration versus water discharge during single hydrologic events in rivers. Journal of Hydrology 111: 89-106.

Wright JP, Jones CG and Flecker AS. (2002) An ecosystem engineer, the beaver, increases species richness at the landscape scale. Oecologia 132: 96-101. 